\title{
Reseña del libro Escritos desobedientes. Historias de hijas, hijos y familiares de genocidas por la memoria, la verdad y la justicia de Analía Kalinec (comp.)
}

\author{
Teresa Basile* \\ Centro de Estudios de Teoria y Critica Literaria, Instituto de Investigaciones en Humanidades \\ y Ciencias Sociales, Universidad Nacional de La Plata, Argentina \\ terebasile@yahoo.com
}

$\mathrm{Si}$, como quería Jorge Luis Borges, una palabra en su infinita concatenación puede engendrar el universo, el término "desobediencia", al menos, despliega una constelación de significaciones. Conecta la infancia obediente de los hijos e hijas de represores (una entera educación normalizadora en el interior de la "familia militar") con la desobediencia elegida en la adultez; señala una rebelión ante la Ley del Padre en el interior del hogar y una insubordinación a las políticas de la Patria militar (y a sus leyes de obediencia debida). Adquiere el estatuto de una categoría teórica en el área de los estudios sobre memoria y se convierte en un dispositivo performativo que presiona a la Justicia con demandas de nuevas leyes para poder declarar en contra de los progenitores. Se vuelve una clave y llave para introducirnos en los retos que los hijos y familiares de genocidas deben enfrentar al tomar la decisión de negar a sus padres (o parientes) y deviene un vocablo articulatorio de nuevas experiencias, voces y políticas en la arena de las luchas por la memoria, verdad y justicia.

Escritos desobedientes se divide en dos partes - más allá del Manifiesto que abre y del Posfacio que cierra el volumen-. La primera de ellas, "Historias de vida", incluye los relatos en primera persona bajo el título que nombra y apellida a quien escribe: esta preeminencia del "yo" promete una enunciación desde el interior privadísimo de la escena familiar que saque a la luz y revele las experiencias de una infancia con un padre, abuelo o familiar represor -cuyo rostro ensaya variantes entre el buen padre, el padre violento en casa o el monstruo represor afuera, entre otros-.

En cambio, los "Relatos desobedientes", la segunda parte, escritos desde un yo comunitario, representativo de la agrupación y de carácter institucional, recorren desde sus mismos títulos los manifiestos, las decisiones y las prácticas públicas y políticas de este organismo creado en 2017. Pero no hay hiato entre ambas partes ya que, como sabemos, "lo personal es político" y aún más en el espacio de la militancia por parte de varios organismos de derechos humanos en Argentina, basados en el vínculo familiar con las víctimas del terrorismo estatal. Incluso, la primera parte aparece como garantía y sostén de la segunda: "el repudio cobra mayor sentido, mayor fuerza, como genuina posición ética, a partir del lazo del afecto" (53), afirma Bibiana Reibaldi y con ello destaca el centro del conflicto que tensa el amor al padre con el rechazo a su conducta, contraponiendo el afecto a la ética.

¿Cómo surgió y se conformó esta agrupación y cuáles son sus líneas conductoras? ¿De qué modo enfrentan sus desafíos en el interior de la familia y cómo exponen sus proyecciones en el exterior de la política? ¿A través de qué mecanismos tramitan su dolor estas subjetividades vulneradas por un acontecimiento traumático y cuáles son sus decisiones como sujetos políticos? 
Como ha acontecido en otros organismos de derechos humanos constituidos por el "familismo" del que habla Elizabeth Jelin, la experiencia de formar una gran familia es muy fuerte. Reconocerse en historias similares que sacudieron sus infancias, en el acto de descubrir la verdad de sus padres o parientes represores, y en la toma de decisión de rechazar sus complicidades con el aparato represivo, les permite a los "hijes desobedientes" salir de ese lugar de culpa y vergüenza, y reconvertirlo en potencia militante, transformar a la gran familia en comunidad política. De allí que insistan en que estos “escritos desobedientes" forman un "relato grupal" (Kalinec: 10).

La toma de la palabra y el ejercicio de la escritura en este relato grupal exhiben una doble dimensión. La palabra es, en primer lugar, catártica y purgatoria, permite sanar las heridas, recomponer las subjetividades dañadas y limpiar la herencia. En este sentido acompaña y vehiculiza el largo y complejo proceso psíquico padecido en el transcurso de desafiliación de la familia militar y reafiliación a espacios alternativos (desde las Madres hasta enclaves simbólicos como los derechos humanos). Esta prolongada tramitación subjetiva suele estar pautada -con múltiples variantes y diferencias- por: el golpe del descubrimiento del rol de represor (generalmente en la reapertura de los juicios alrededor de la primera década del siglo XXI, que viene a coincidir con la madurez de los hijos e hijas); las primeras negaciones y justificaciones para afirmar la inocencia de los progenitores; el acecho de las dudas y la búsqueda de información; las preguntas, diálogos e interpelaciones a sus padres; el consiguiente rechazo al padre represor, el enfrentamiento con la familia y la expulsión del hogar; la necesidad de conocer a las víctimas y solidarizarse con ellas. Todo lo cual suele estar acompañado de un tratamiento terapéutico para transitar la angustia, para quitarse la acusación de traicionar a quien lo crió, para encontrar una salida a la irresoluble tensión entre los afectos y la ética, para limpiar la culpa heredada, para quitarse el estigma del "huevo de la serpiente", según cada caso.

La necesidad de volver a engendrarse, de parirse a sí mismos, de volver a nacer habla del profundo golpe a la identidad sufrido por los hijos e hijas, que atañe tanto a la recomposición identitaria íntima y personal de quien descubre que vivía en un engaño, como a la destrucción de un universo de valores, costumbres y saberes que se derrumba quitando los cimientos que sostenían al yo. Así Oscarina $\mathrm{H}$ reconoce el imperativo de desarmar aquello que había "internalizado" en el hogar de su infancia: las aseveraciones sobre la última dictadura y el "proceso", las formas de establecer vínculos y concebir la familia, el amor, el poder, la autoridad, la sociedad, el sexo, la salud, los gobiernos, la política, la educación, la religión, Dios, el mundo, todas "formas y costumbre que son del clan" (134). El "machismo" presente en la familia militar suele ser una nota constante en estas historias de vida, que luego impulsa la militancia feminista.

Este salto identitario suele tener un ingrediente purgatorio y puede conducir a solicitar un cambio de apellido en el DNI o a renombrarse con un apodo como el "Topo" "“la vida me renombró. Con el "Topo" vino el arte, las ideas de izquierda, el amor de seres con familiares desaparecidos, y todo ese Jordán que me liberó del pecado original”, 149), o a solicitar por vía judicial el reconocimiento legal -cuando se entera que su padre es un represor que lo abandonó al nacer- de que es hijo de un genocida, lo que lo autoriza a testimoniar contra su padre: "gracias a ello tengo el derecho a decir estas palabras" (141). La purificación también concierne a la estirpe, a la herencia manchada que es necesario limpiar para restablecer la transmisión generacional hacia los antepasados -como el reclamo que le hace en sueños su tía abuela Josefina a Lizi Raggio desde el cementerio (93-97) - y hacia los propios hijos: "para que mis hijos y mis nietos no carguen con el peso del horror y el silencio" (96). 
El segundo valor de la palabra es ético-político e implica: oponerse al pacto de silencio asumido por los progenitores militares; exigirles a sus padres que se arrepientan, que pidan perdón y que entreguen información sobre los desaparecidos y los niños apropiados (con este pedido se diferencian de quienes apuestan a la reconciliación), exigir a la justicia un cambio de leyes que les permita declarar como testigos en las causas contra sus padres y familiares. Este ejercicio de la palabra se ha dado a conocer en diversos medios, desde el Facebook de Historias Desobedientes hasta las publicaciones en la Agencia Nacional de Noticias Télam. El presente volumen es parte central de los testimonios en torno a la última dictadura argentina y se integra a un abultado corpus, dialogando especialmente con los testimonios de la segunda generación esgrimidos por los hijos e hijas de detenidos desaparecidos y víctimas del terrorismo estatal, así como también con aquellos hijos e hijas de represores que defienden a sus padres y reclaman una "memoria completa", una "verdad total".

No deberíamos desconocer, en tercer lugar, las inflexiones de la palabra, su cualidad estética que da lugar a una escritura maldiciente, atravesada por la violencia, una voz malhablada y punzante, de protesta y militancia, oral y vociferada, indignada ante las injusticias, por un lado, y por el otro, a una escritura melancólica, que lamenta la pérdida, sufre el exilio del hogar y añora el extravío del vínculo familiar, es una escritura del afecto amoroso y la nostalgia, es una lengua irremediablemente dañada por el dolor, que busca un consuelo imposible, que solloza.

La palabra no sólo recuerda el pasado, se vuelve presente para, además, sumar nuevos reclamos en torno a los derechos humanos durante el gobierno de Mauricio Macri, como las protestas frente al intento de aplicar la ley del " $2 \times 1$ " que beneficiaba a los culpables de los crímenes de lesa humanidad, la participación en la marcha de Ni Una Menos, la crítica al discurso "negacionista” respecto a los 30.000 desaparecidos, el señalamiento de nuevas desapariciones como la de Santiago Maldonado, la oposición a las prisiones domiciliarias para los represores, la negativa a convertir Campo de Mayo en un Parque Nacional que impida el hallazgo de nuevas pruebas junto al pedido para que se lo reconozca como sitio de memoria, los fuertes reparos contra el endeudamiento con el FMI y la condena a la represión de la protesta social, entre otros puntos.

Lejos de cualquier clausura o cristalización, las luchas por la memoria siguen en pie ya que la memoria es, como sostiene Carolina Bartalini, "revoltosa y revolucionaria" (15). Escritos desobedientes constituye, como asegura María Laura Delgadillo, "una pieza que faltaba para completar la historia” (78).

\section{Notas}

1 Kalinec, Analía (comp.). Escritos desobedientes. Historias de hijas, hijos y familiares de genocidas por la memoria, la verdad y la justicia. Ciudad Autónoma de Buenos Aires: Marea, 2018.

\section{Notas DE AUTOR}

\footnotetext{
Teresa Basile es Doctora en Letras por la Facultad de Humanidades y Ciencias de la Educación de la Universidad Nacional de La Plata (UNLP), y Magister en Letras Hispánicas por la Universidad Nacional de Mar del Plata. Es Directora del Centro de Teoría y Crítica Literaria (IDIHCSCONICET-UNLP), se desempeña como Profesora Adjunta en la cátedra de Literatura Latinoamericana II y dicta seminarios sobre Literatura y Memoria en la Maestría en Historia y Memoria (UNLP). Ha publicado El desarme de Calibán. Debates culturales y diseños literarios en la posdictadura uruguaya (Instituto Internacional de Literatura Iberoamericana-IILI, Pittsburgh, 2018), Infancias. La narrativa argentina de HIJOS (EDUVIM, 2019) y numerosos volúmenes colectivos que abordan los vínculos entre literatura, política y memoria en las literaturas latinoamericanas de las últimas décadas.
} 